
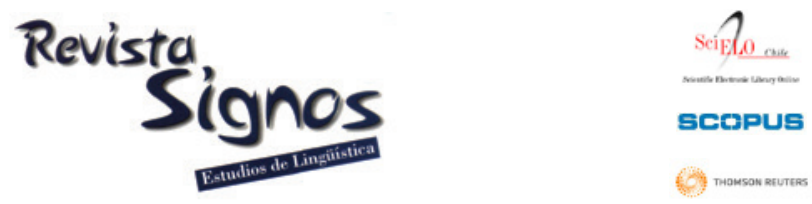

\title{
Evaluación de la conciencia sintáctica: Efectos de la verosimilitud en la resolución de tareas y en su relación con la comprensión de oraciones ${ }^{*}$
}

\section{Assessment of syntactic awareness: Effects of plausibility in solving tasks and in its relation to sentence comprebension}

\author{
Juan José Navarro \\ Universidad Autónoma de Chile, Chile \\ Universidad de SeVilla, España \\ jjnavarro@uatonoma.cl-jjnavarro@us.es
}

\author{
Isabel de los Reyes Rodríguez \\ Universidad de SEVILLA \\ ESPAÑA \\ ireyes@us.es
}

Recibido: 28-IX-2012 / Aceptado: 30-VII-2013

\section{Resumen}

En este estudio se presenta una tarea de evaluación de la conciencia sintáctica. La tarea consiste en ordenar frases previamente desordenadas. Las frases se diferencian en longitud (corta-larga), complejidad sintáctica (activa-pasiva, simple-compuesta, coordinada-subordinada) y verosimilitud (la mitad de las oraciones son semánticamente verosímiles y la mitad inverosímiles). Se analiza la información proporcionada por esta tarea en su aplicación a un grupo de 97 estudiantes del tercer ciclo de educación primaria ( $5^{\circ}$ y $6^{\circ}$ curso) y se comparan los resultados en función de cada una de las condiciones contempladas, así como del nivel de comprensión de oraciones. Los resultados confirman mayores dificultades cuando el contenido es semánticamente inverosímil, haciendo imprescindible el uso de estrategias de procesamiento sintáctico. Los datos muestran también que si bien la longitud y algunos elementos de complejidad sintáctica muestran efectos significativos sobre los resultados, la introducción de oraciones semánticamente inverosímiles constituye una mayor dificultad de forma generalizada, modulando el efecto producido por las anteriores condiciones. Los datos no revelan diferencias en comprensión entre estudiantes con un perfil lector 'sintáctico' y aquellos con perfil 'semántico'. Finalmente, constatamos que aquellos ítems de la tarea que permiten un procesamiento semántico, se relacionan mejor con la medida de comprensión que los ítems que solo admiten un procesamiento sintáctico. Los resultados sugieren que la tarea aplicada permite obtener información diferenciada en relación a los componentes sintáctico y semántico del lenguaje escrito en procesos de evaluación de la lectura.

Palabras Clave: Complejidad sintáctica, conciencia sintáctica, comprensión lectora, estrategias sintácticas. 


\begin{abstract}
In this study, we present one task to assess syntactic awareness. This task consists in rearranging the word order in a set of sentences. The sentences vary in length (short-long), syntactic complexity (active-passive, simple-compound, coordinatedsubordinated) and plausibility (half of the sentences are semantically plausible and the other half are semantically implausible). We analyzed the information provided by this task in its application to a group of 97 primary students, and we compared the results based on each of the conditions and depending on the level of understanding. The results show greater difficulty when the content is semantically implausible, making essential the implementation of syntactic processing skills. The data also show that while some elements of length and syntactic complexity show significant effects on the results, the introduction of semantically implausible sentences overwhelmingly affects task performance, modulating the effect of the aforementioned conditions. The data reveal no differences in comprehension among students who had a syntactic reader profile and those with a semantic reader profile. Finally, we found that those items in the task that allow for semantic processing relate better to the measure of reading comprehension than the items that support only syntactic processing. The results suggest that the designed task allowed to obtain differentiated information about the syntactic and semantic components of written language in the process of reading assessment.
\end{abstract}

Key Words: Reading comprehension, syntactic awareness, syntactic complexity, syntactic strategies.

\title{
INTRODUCCIÓN
}

El presente estudio se enmarca en la investigación relativa a la evaluación de la conciencia sintáctica (CS) y sus relaciones con la comprensión. En los últimos años, la investigación está aportando nuevos datos que ponen de relieve la importancia del procesamiento de estructuras morfosintácticas en el proceso de lectura y comprensión, así como en la explicación de las dificultades específicas que experimentan algunos estudiantes (Nation \& Snowling, 2000; Soriano, Pérez \& Domínguez, 2006; Cain, 2007; Jiménez, Rodríguez, Guzmán \& García, 2010). Parece ser que para que este tipo de procesamiento pueda tener lugar de modo eficaz en el ámbito del lenguaje escrito, es imprescindible un cierto grado de CS, entendida esta como el conocimiento consciente o metaconocimiento acerca de las estructuras gramaticales y de la función que desempeña cada uno de los elementos que la componen (Gombert, 1992). La investigación precedente en este campo recoge diversas tareas desarrolladas con el objetivo de evaluar esta CS (Layton, Robinson \& Lawson, 1998; Nation \& Snowling, 2000; Cain, 2007; Andrés, Conet \& García, 2010; Miller, 2010). En este sentido, uno de los hallazgos más importantes que se deduce de los estudios es la distinta sensibilidad mostrada por algunas de estas tareas en su relación con medidas de la 
comprensión y el reconocimiento de palabras (Cain, 2007), lo que sugiere que podrían estar actuando sobre distintos procesos implicados en el procesamiento sintáctico.

Asimismo, son diversos los problemas con los que se ha enfrentado la investigación en este ámbito, principalmente de carácter metodológico y de configuración del contenido de las tareas. Aspectos como la interferencia de la memoria de trabajo en la resolución de las actividades, el conocimiento previo de estructuras gramaticales, el vocabulario, o el uso de estrategias de procesamiento semántico, constituyen variables que en definitiva dificultan una valoración precisa de la CS y de su relevancia específica en la explicación de la comprensión de textos. En este sentido, quizás el problema esencial ha consistido en la dificultad de aislar los componentes sintáctico y semántico en el proceso de evaluación.

En consecuencia, el presente estudio pretende esencialmente analizar cómo afecta la condición verosimilitud (oraciones verosímiles-inverosímiles) en la resolución de una tarea de evaluación de la CS, y de qué forma se relaciona esto con el nivel de comprensión de oraciones. De este modo, se pretende obtener información diferenciada en relación a los componentes y estrategias de procesamiento sintáctico y semántico en la evaluación de la propia CS y en su relación con la comprensión.

\section{Bases teóricas de la conciencia sintáctica}

La CS es una habilidad metalingüística que comienza a desarrollarse antes de la escolarización obligatoria, experimentando, al igual que otros aspectos del desarrollo metalingüístico, un incremento notable en contacto con la educación formal (Ball, 1997; Wigfield \& Asher, 2002). En la práctica, la CS funcionaría a modo de patrón en el que podemos encajar las distintas piezas (categorías gramaticales) que conforman el discurso. Estos patrones sintácticos son de algún modo internalizados durante el aprendizaje del lenguaje en estrecha interdependencia con el desarrollo de otros componentes lingüísticos y en función de la experiencia y el contexto sociocultural de referencia (McCune, 2008; Serrat, Sanz-Torrent, Badia, Aguilar, Olmo \& Lara, 2010), configurando representaciones mentales que otorgan estructura al lenguaje. El procesamiento sintáctico implica asimismo tener en cuenta diversas claves, como los signos de puntuación, los marcadores morfológicos o la propia estructura gramatical, es decir, el orden de las palabras en la oración y las distintas combinaciones de elementos (sintagmas y complementos) que pueden modificar el significado del mensaje y complejizar su comprensión. De este modo, algunas estructuras gramaticales pueden suponer una dificultad añadida. Tal es el caso de las estructuras pasivas, las oraciones subordinadas de relativo, las oraciones de estructura Sujeto-Verbo-Objeto con objeto escindido o las oraciones con estructura Objeto-Verbo-Sujeto con objeto focalizado (Cuetos, 2008).

Con base en las definiciones habituales de otras habilidades metalingüísticas como la conciencia fonológica y la morfológica (Tunmer \& Herriman, 1984; 
Gombert, 1993; Miller, 2010; Tong, Deacon, Kirby, Cain \& Parrila, 2011), la CS implica la habilidad para acceder, y manipular consciente y deliberadamente, a los aspectos sintácticos del lenguaje hablado o escrito, especialmente la estructura gramatical de las oraciones (Andrés et al., 2010). Asumiendo que la comprensión y el procesamiento de la información contenida en un texto tiene lugar de modo interactivo, conjugando continuamente procesos de identificación y reconocimiento de palabras con la elaboración de hipótesis o la activación de conocimientos previos (Perfetti, Landi \& Oakhill, 2005), la conciencia y el procesamiento sintácticos implican una consideración específica de la estructura gramatical, pudiendo situarse su análisis más allá del significado concreto de un texto (Cain, 2007). Este hecho tiene implicaciones relevantes, no solo porque es posible analizar un texto en función de sus características morfosintácticas, sino porque posibilita analizar en qué medida las dificultades de un sujeto se circunscriben a la morfosintaxis.

Asimismo, esta CS es sumamente importante en el proceso de detección de errores en la propia estructura gramatical, alertándonos cuándo una determinada estructura no se ajusta al patrón que hemos configurado (Oakhill \& Cain, 2005). Por otra parte, aunque es posible acceder conscientemente a nuestros conocimientos sobre estructuras gramaticales y ejercer un control intencional en relación a estas, es preciso destacar que la mayor parte del procesamiento sintáctico y morfosintáctico del lenguaje escrito, lo efectuamos de modo automatizado, lo que contribuye significativamente a liberar recursos que permitan abordar actividades complejas relacionadas con la integración textual y la comprensión (Cuetos, 2008).

\subsection{Conciencia sintáctica y comprensión lectora}

Un aspecto esencial en este campo de estudio es la relación entre CS y habilidades lectoras y de comprensión de textos. En este sentido, se han observado correlaciones significativas con medidas de decodificación y de comprensión de oraciones (Bowey \& Patel, 1988; Demont \& Gombert, 1996; Andrés et al., 2010). Con relación a la decodificación, la CS favorecería los procesos de reconocimiento de palabras, actuando a modo de corsé que reduce las opciones y facilita la decodificación de palabras desconocidas (Tunner \& Hoover, 1992; Rego \& Bryant, 1993). En cuanto a la comprensión, contribuye facilitando, por una parte, la integración lineal de las ideas y la conexión entre el nivel de procesamiento de la oración y el nivel del texto, y por otra, constituyéndose en una habilidad de supervisión del proceso de comprensión, debido a que, como apuntábamos anteriormente, actuaría a modo de detector de posibles errores sintácticos (Tunner \& Bowey, 1984; Bowey, 1986). Se asume que un bajo nivel de CS incidiría significativamente en el procesamiento de las estructuras gramaticales, lo que terminaría repercutiendo en la comprensión efectiva del texto (Tunmer \& Bowey, 1984). Si bien los datos de diversos estudios aportan evidencias que relacionan CS y comprensión, lo cierto es que esta relación podría estar en mayor o menor medida mediatizada por el conocimiento de estructuras gramaticales, el vocabulario o la memoria de trabajo (Cain, 2007). Más clara parece la relación existente entre CS 
y reconocimiento de palabras (Demont \& Gombert, 1996; Gottardo, Stanovich \& Siegel, 1996; Cain, 2007). En este sentido, se ha encontrado una relación significativa entre medidas de CS y la mayor precisión en la lectura contextualizada de palabras (Muter \& Snowling, 1998), ejerciendo a su vez esta relación una influencia indirecta sobre los niveles de comprensión. De este modo, a través de la influencia ejercida sobre la decodificación y la comprensión auditiva, la CS ha logrado predecir de forma estable (hasta un año después) la comprensión lectora de niños de primer curso (Tunmer, 1989).

En relación a los efectos del entrenamiento sobre la comprensión, algunos estudios revelan que, a pesar de que la CS puede mejorarse con entrenamiento específico, las ganancias observadas pueden no reflejarse finalmente en la mejora de las habilidades lectoras de los estudiantes. En un estudio instruccional, Layton et al. (1998), compararon dos grupos de estudiantes de cuarto grado que recibieron respectivamente entrenamiento sintáctico-semántico, utilizando como base tareas tipo Cloze, y entrenamiento solo semántico (discusión sobre el significado de las palabras), utilizando el mismo material. El entrenamiento del grupo experimental consistió en favorecer el uso del contexto para identificar las palabras omitidas, recibiendo retroalimentación en relación a los errores cometidos y favoreciendo la indagación y la toma de conciencia acerca de la relevancia de tener en cuenta las reglas gramaticales para poder realizar con éxito la tarea. Los resultados mostraron que el grupo experimental obtuvo mejores resultados en CS que el grupo de control, aunque estos resultados no se tradujeron en ganancias significativas en comprensión ni tampoco en las medidas de precisión lectora.

Por otra parte, la investigación ha puesto también de manifiesto diferencias significativas entre lectores competentes y con bajo nivel de comprensión en relación a sus niveles de CS (Bowey, 1986; Nation \& Snowling, 2000). En un estudio con estudiantes de cuarto y quinto grado que diferían en su nivel de decodificación, Bowey (1986) analizó la hipótesis de que los lectores menos hábiles adquirían más lentamente habilidades de CS que los lectores competentes y que este retraso en la adquisición de la habilidad estaba asociado con errores relativos a las habilidades de supervisión de la comprensión lectora. Utilizando una medida de corrección de errores gramaticales en tareas de lenguaje oral, los resultados mostraron diferencias en CS, controlados los efectos de habilidad verbal general. Asimismo, la actuación en la tarea correlacionó con medidas de supervisión de la comprensión lectora y con la actuación en tests estandarizados de comprensión.

\subsection{La evaluación de la conciencia sintáctica}

Es preciso destacar, cómo apuntábamos en la introducción, que las diferentes pruebas utilizadas para evaluar la CS parecen mostrar una sensibilidad distinta en su relación con las habilidades lectoras y la comprensión (Cain, 2007). Este aspecto hace 
imprescindible efectuar análisis independientes en función de las tareas empleadas en los estudios, así como analizar minuciosamente su contenido y precisar el peso que las tareas en sí y sus distintos componentes sintácticos y semánticos, puedan estar teniendo en las conclusiones acerca de las relaciones entre CS y lectura. Entre las tareas más utilizadas se encuentran las de estructuración gramatical, completar oraciones en las que falta un elemento, juicio de gramaticalidad, ordenación de frases previamente desordenadas, detección/corrección de errores gramaticales, responder preguntas que requieren atender exclusivamente a claves sintácticas, o cuestionarios de evaluación del metaconocimiento sintáctico (Layton et al., 1998; Nation \& Snowling, 2000; Cain, 2007; Andrés et al., 2010; Miller, 2010). En este sentido, uno de los inconvenientes que han sido descritos en relación a la aplicación de algunas de estas tareas, especialmente las de corrección gramatical y ordenación de frases desordenadas, ha sido la sobrecarga de memoria de trabajo (MT) necesaria para ejecutar los ejercicios cuando estos son planteados de forma exclusivamente oral. De este modo, se hace necesario mantener operativa en la memoria una secuencia de palabras que deben ser analizadas para detectar y corregir el error, o bien para proceder a ordenar correctamente la secuencia. Esto supone ciertamente que la MT juegue un papel fundamental en la ejecución de las tareas tal y como han sido planteadas en la mayoría de estudios. Aunque esta variable pueda ser controlada mediante la aplicación de una prueba específica, lo cierto es que su influencia puede dificultar en exceso el análisis del objeto de estudio, en este caso, la capacidad para reflexionar y manipular explícitamente los aspectos sintácticos del lenguaje ejerciendo un control consciente sobre la aplicación de las reglas gramaticales. Una posibilidad de minimizar la influencia de la MT en estas tareas consiste en que el sujeto pueda leer y disponer en todo momento del material escrito (Andrés et al., 2010). Al permanecer presentes los estímulos, el objetivo no incluye recordar y mantener operativa la secuencia de palabras, sino que se centra en detectar, corregir u ordenar los elementos.

Otro de los aspectos relevantes en relación a las tareas, tiene que ver con el contenido de los estímulos. Cain (2007) emplea frases desordenadas distinguiendo entre aquellas que no ofrecen la posibilidad de reversibilidad semántica, por ejemplo, "corre autobús del detrás niño el", y aquellas que son semánticamente reversibles: "corre del detrás burro perro el". La lógica de esta distinción responde a las mayores posibilidades de aplicación de estrategias de procesamiento sintáctico-semántico en las primeras (Bowey, 1994; Nation \& Snowling, 2000). En sus estudios, basados en tareas de aplicación oral, Cain (2007) muestra cómo efectivamente, la estrategia de procesamiento sintáctico-semántico requerida en la tarea de ordenación de frases basada en el significado, acentuó la relación entre CS y comprensión en estudiantes de 9-10 años, explicando adicionalmente una proporción de la varianza, una vez controladas las variables vocabulario, conocimiento de estructuras gramaticales y MT. Sin embargo, las frases semánticamente reversibles, con mayor carga de procesamiento sintáctico, no mostraron esta relación significativa con la comprensión. No obstante, la reversibilidad semántica podría no ser suficiente para establecer una medida 
ajustada del procesamiento sintáctico sin interferencia de los aspectos semánticos. En este sentido, es posible evaluar la CS con frases desordenadas que no presentan un significado lógico y verosímil, por ejemplo: “comen taller. con sillas Las el”. En esta frase solo es posible aplicar una solución que sea sintáctica y morfológicamente correcta, a pesar de que una vez ordenada el sentido no sea lógico o verosímil desde una perspectiva semántica. De este modo, es posible analizar la capacidad de estructurar y comprender un mensaje atendiendo exclusivamente a las claves sintácticas y a la función que desempeñan las distintas categorías gramaticales. En este sentido, es preciso señalar la necesidad de nuevas investigaciones que aporten información en relación a los procesos críticos que permiten evaluar la conciencia sintáctica, y que asimismo permitan obtener una mayor comprensión de los componentes sintácticos y semánticos implicados en la comprensión. Son precisamente estos aspectos los que constituyen el núcleo esencial de la investigación que presentamos.

\subsubsection{El presente estudio: Objetivos e hipótesis de trabajo}

En consonancia con el objetivo general de evaluar el efecto de la condición verosimilitud en la resolución de una tarea de evaluación de la CS, y del modo en que esto se relaciona con la comprensión de oraciones y permite obtener información diferenciada sobre componentes y estrategias de procesamiento sintáctico y semántico, hemos planteado tres objetivos específicos. Estos objetivos consisten en: (1) analizar el efecto diferencial de la verosimilitud, la longitud de las oraciones y la complejidad gramatical, en la ejecución de una tarea consistente en ordenar frases previamente desordenadas; (2) diferenciar entre perfiles lectores en función del uso de estrategias sintácticas y/o semánticas; y (3) comprobar en qué medida la tipología de ítems utilizada podría condicionar la relación existente entre CS y comprensión. En función de estos objetivos y de la literatura revisada, esperamos encontrar un efecto significativo y diferencial de la condición verosimilitud (oraciones verosímiles-inverosímiles) en los resultados obtenidos de la evaluación de la CS, posibilitando este efecto la configuración de distintos perfiles lectores y permitiendo asimismo comprobar su influencia en la relación existente entre CS y comprensión. En consecuencia, se han formulado cuatro hipótesis de trabajo que responden a los objetivos específicos anteriormente mencionados. Las dos primeras hipótesis se relacionan con el objetivo (1), sosteniendo la primera de ellas que las frases semánticamente inverosímiles supondrán una mayor dificultad lectora para los estudiantes en comparación con las verosímiles (Cain, 2007; Miller, 2010) (hipótesis 1); por su parte, la segunda hipótesis prevé que la condición de verosimilitud y por tanto, la consideración de niveles diferentes de exigencia en el uso de estrategias sintácticas, tenga un mayor peso que la complejidad sintáctica y la longitud a la hora de explicar los resultados, así como las dificultades encontradas (hipótesis 2). En consonancia con el objetivo (2), en relación a los distintos perfiles lectores, se aventura que los lectores 'sintácticos' (aquellos con puntuaciones altas en la ordenación de frases inverosímiles y verosímiles) van a tener una mayor puntuación en comprensión que los lectores 'semánticos' (aquellos con bajas puntuaciones en la 
ordenación de frases inverosímiles, pero con puntuaciones altas en las verosímiles) y que ambos tipos de lectores serán superiores en comprensión a los lectores 'anómalos' (con bajas puntuaciones en ambos tipos de frases) (hipótesis 3). Por último, con relación al objetivo (3), esperábamos confirmar que la tipología de ítems (verosímilesinverosímiles) influiría significativamente en la relación que mantiene la CS con el nivel de comprensión. En este sentido, los ítems con mayor carga de procesamiento semántico presentarían un mayor índice de relación con el nivel de comprensión que aquellos ítems que dependen en mayor medida de un procesamiento sintáctico (Cain, 2007) (hipótesis 4).

\section{Marco metodológico}

\subsection{Diseño y participantes}

El presente estudio analiza, desde un enfoque descriptivo-comparativo y correlacional, la información diferencial proporcionada a raíz de la aplicación a un grupo de estudiantes de educación primaria de una tarea de evaluación de la CS, consistente en la ordenación de frases previamente desordenadas que difieren en longitud, complejidad sintáctica y verosimilitud. Se comparan los resultados en función de la dificultad y del peso de cada una de las condiciones contempladas y se analizan los efectos de la condición verosimilitud en la relación que establecen CS y comprensión de oraciones. La muestra la componen 97 estudiantes de educación primaria pertenecientes a un mismo centro público de Sevilla (Andalucía-España). Cuarenta y ocho estaban escolarizados en dos clases de $5^{\circ}$ curso (31 chicos y 17 chicas), y 49 en dos clases de $6^{\circ}$ ( 23 chicos y 26 chicas). Se trata de estudiantes de aulas regulares, sin dificultades específicas de aprendizaje ni ninguna otra circunstancia especial reseñada por sus profesoras. La media de edad se situó en $10.98(D T=0.78)$. El nivel sociocultural de la muestra puede ser catalogado de medio.

\subsection{Instrumentos}

\subsubsection{Medida de la conciencia sintáctica}

Hemos utilizado una prueba de evaluación de la CS basada en la ordenación de frases previamente desordenadas (CS-ORD) (Navarro \& Rodríguez, 2011). En la prueba se presentan 24 frases desordenadas que cada participante debe ordenar según las reglas gramaticales del español. Las frases difieren en longitud, complejidad sintáctica y verosimilitud. Las frases que contienen hasta cuatro elementos se consideran cortas y las frases con más de cuatro elementos se consideran largas (Soriano et al., 2006). Las frases formadas por un solo verbo se consideran simples y por más de un verbo, compuestas. Dentro de estas últimas, se consideran coordinadas las oraciones formadas por dos frases que mantienen relación de significado pero sintácticamente son independientes y se reserva la categoría de subordinadas para aquellas oraciones compuestas en las que entre las proposiciones se establece una 
relación de dependencia sintáctica (Alarcos, 2000). Por último, la mitad de las frases son verosímiles, es decir, se refieren a eventos posibles en la vida diaria, y el resto son frases inverosímiles porque contienen significados que contradicen el conocimiento previo o hacen referencia a hechos imposibles o improbables. Todas las palabras incluidas en las frases son de frecuencia alta (frecuencia superior a 10), según el léxico informatizado del español, LEXESP de Sebastián, Martí y Carreiras (2000). De esta manera, el instrumento consta de doce frases simples (S) y doce compuestas (C). Entre las simples, cuatro son cortas (SC): dos verosímiles (SCV) y dos inverosímiles (SCI), todas activas; y ocho son largas (SL): cuatro activas, dos verosímiles (SLVA) y dos inverosímiles (SLIA), y cuatro pasivas-reflexivas, dos verosímiles (SLVP) y dos inverosímiles (SLIP). Por su parte, entre las frases compuestas (todas ellas largas), cuatro son coordinadas (CC): dos verosímiles (CCV) y dos inverosímiles (CCI); y ocho son subordinadas (de relativo y condicionales): cuatro verosímiles (CSV) y cuatro inverosímiles (CSI).

Las frases se presentan desordenadas, pero cada palabra está acompañada en su caso del signo de puntuación con el que aparece en la frase original, por ejemplo, "bebe gata La agua." en la primera frase de la prueba. Asimismo, la primera palabra de la frase original mantiene la letra mayúscula inicial cuando la frase se desordena, como podemos comprobar en el ejemplo anterior. En el instrumento las cuatro primeras frases son las frases cortas y el resto de frases aparece aleatorizado, pero teniendo en cuenta que el número de palabras de cada frase siga un orden creciente. $\mathrm{Al}$ inicio de la prueba aparecen cuatro ítems de ensayo. La puntuación máxima que es posible alcanzar es de 24 puntos, obteniéndose un punto por acierto. En este sentido, se consideró acierto cuando la frase estaba correcta y completamente ordenada, tomando en consideración los signos de puntuación y la presencia de la mayúscula.

Con la tarea CS-ORD pretendemos evaluar un aspecto relativo a la CS que consideramos esencial, y que hace referencia a la capacidad para acceder conscientemente al propio conocimiento sintáctico y manipular intencional y deliberadamente elementos de la estructura gramatical que permiten dar coherencia a los textos. Dado que el contenido de las tareas empleadas habitualmente para evaluar la CS, así como los métodos de evaluación, podrían tener una repercusión notable en los resultados y en la interpretación que de estos se hace en la investigación precedente (Layton et al., 1998; Cain, 2007), nos parece oportuno, tal y como plantean Layton et al. (1998), tratar de catalogar la tarea presentada en función de los niveles de conciencia metalingüística descritos por Gombert (1992). Este autor describe cuatro niveles que van de menor a mayor grado de conciencia reflexiva. El nivel (1) reflejaría un conocimiento tácito de las reglas sintácticas; el nivel (2) reflejaría la habilidad de reflexionar y manipular los elementos estructurales del lenguaje; el nivel (3) hace referencia a la habilidad de reflexionar sobre la existencia de reglas gramaticales y de identificar lo que éstas representan; y el nivel (4) se caracteriza por la habilidad de reflexionar sobre los propios conocimientos acerca de las reglas sintácticas o sobre la 
propia actuación en tareas que requieren conocimiento sintáctico. En este sentido, si bien nuestra tarea requiere la reflexión y manipulación deliberada de los elementos de la estructura sintáctica (nivel 2), su ejecución, especialmente en aquellos casos en los que las oraciones no responden a los conocimientos y experiencias previas y no reflejan un significado lógico y esperable, requeriría de reflexión sobre las reglas gramaticales, debiendo evaluar su grado de ajuste con los patrones sintácticos previamente establecidos (nivel 3).

\subsubsection{Medida de la comprensión de oraciones}

Para medir este aspecto hemos utilizado una tarea de evaluación basada en la comprensión de oraciones (Navarro \& Rodríguez, 2011). Esta prueba se fundamenta en una diseñada por Miller (2010) con el mismo propósito. La prueba consiste en presentar una oración y a continuación una pregunta referida a uno de los personajes que han aparecido en la oración. Cada estudiante debe elegir la respuesta correcta entre tres opciones correspondientes a tres elementos que han aparecido en la oración inicial. La opción correcta se contrabalancea a lo largo del instrumento, de manera que, el mismo número de veces la opción correcta aparece en la posición 'a' que en la posición 'b' o en la 'c'. En el instrumento diseñado por Rodríguez y Navarro (2011) se presentan 32 oraciones, todas ellas formadas por palabras de alta frecuencia según el léxico informatizado del español LEXESP de Sebastián et al. (2000). La mitad de las oraciones son simples (formadas por un solo verbo) y la otra mitad son compuestas (formadas por más de un verbo). Las oraciones simples se dividen a partes iguales entre activas y pasivas. Las oraciones compuestas se dividen en coordinadas y subordinadas. La mitad de las preguntas van dirigidas al sujeto que realiza la acción (sujeto) y la otra mitad al sujeto que recibe la acción (objeto). De este modo, el instrumento consta de dieciséis frases simples $(\mathrm{S})$ y dieciséis compuestas (C). En las frases simples hay ocho activas-transitivas (ST) y ocho pasivas (SP). Por su parte, en las frases compuestas, hay ocho coordinadas (CC) y ocho subordinadas (CS). Asimismo, la mitad de las oraciones que componen la prueba tienen sentido lógico o verosímil (se corresponden con hechos posibles) y la otra mitad son inverosímiles. En función de los objetivos del presente estudio se han tomado en consideración solo las 16 oraciones con sentido lógico o verosímil, adoptándose las respuestas otorgadas bajo esta condición como medida de comprensión de oraciones, controlada la frecuencia de uso de las palabras. (Para consultar los instrumentos completos, ver http://bscw.rediris.es/pub/bscw. cgi/4616527)

\subsection{Procedimiento}

Tanto la tarea de ordenación de frases como la medida de comprensión se aplicaron de forma grupal en el aula correspondiente. Se concedieron 30 minutos para la realización de cada una de las pruebas. En la tarea CS-ORD se proporcionaron las instrucciones y se realizaron los cuatro ítems de ejemplo de la página inicial. Cuando 
se comprobó que todos los participantes del grupo entendían las instrucciones de la tarea, se inició su realización. En las instrucciones se demandaba que se ordenaran las frases que se presentaban y que en algunos casos esas frases podían tener sentido lógico y en otros no. En la tarea de comprensión se dijo a los participantes que debían leer con atención las frases y la pregunta que las acompañaba y responder a la misma seleccionando una de las tres opciones de respuesta que aparecían debajo de la pregunta. Se realizaron de forma grupal los cuatro ejemplos que aparecen en la página inicial del instrumento, comenzando la tarea una vez que todos los participantes habían entendido las instrucciones.

\section{Resultados}

\subsection{Estadísticos descriptivos y análisis de propiedades psicométricas}

En la Tabla 1 mostramos los estadísticos descriptivos correspondientes a los resultados obtenidos en la tarea CS-ORD, incluyendo las distintas condiciones contempladas. Asimismo, mostramos en la Tabla 2 los promedios y la desviación típica correspondientes a la tarea de comprensión de oraciones, especificando las puntuaciones obtenidas en las distintas estructuras contempladas.

Tabla 1. Media y desviación típica para cada una de las condiciones contempladas en la tarea CS-ORD y para el total $(N=97)$.

\begin{tabular}{|l|c|c|l|c|c|}
\hline Condiciones Tarea CS-ORD & Media & $\boldsymbol{D T}$ & Condiciones Tarea CS-ORD & Media & $\boldsymbol{D T}$ \\
\hline Simple Larga Activa & 2.33 & 1.09 & Simple Larga Pasiva & 2.65 & 1.04 \\
\hline Simple Corta Verosímil & 1.96 & 0.20 & Simple Corta Inverosímil & 1.96 & 0.25 \\
\hline Simple Larga Verosímil & 3.01 & 0.95 & Simple Larga Inverosímil & 1.97 & 1.13 \\
\hline Compuesta Coordinada Verosímil & 0.56 & 0.71 & Compuesta Coordinada Inverosímil & 0.21 & 0.41 \\
\hline Compuesta Subordinada Verosímil & 0.97 & 0.86 & Compuesta Subordinada Inverosímil & 0.12 & 0.39 \\
\hline Simple Corta & 3.92 & 0.40 & Simple Larga & 2.42 & 1.10 \\
\hline Compuesta Coordinada & 0.76 & 0.85 & Compuesta Subordinada & 1.09 & 1.03 \\
\hline Simple Verosímil & 4.97 & 0.98 & Simple Inverosímil & 3.93 & 1.18 \\
\hline Compuesta Verosímil & 1.53 & 1.21 & Compuesta Inverosímil & 0.33 & 0.61 \\
\hline Total Simple & 8.90 & 1.85 & Total Compuesta & 1.86 & 1.51 \\
\hline Total Verosímil & 6.49 & 1.75 & Total Inverosímil & 4.26 & 1.42 \\
\hline Media Total = 10.75 (DT $=2.75)$ & & & & \\
\hline
\end{tabular}


Tabla 2. Media y desviación típica para la tarea de comprensión $(N=97)$.

\begin{tabular}{|l|c|c|l|c|c|}
\hline Tarea de comprensión & Media & $\boldsymbol{D} \boldsymbol{T}$ & Tarea de comprensión & Media & $\boldsymbol{D} \boldsymbol{T}$ \\
\hline Simple Activa-Transitiva & 3.92 & 0.34 & Simple Pasiva & 3.85 & 0.46 \\
\hline Compuesta Coordinada & 3.86 & 0.56 & Compuesta Subordinada & 3.85 & 0.53 \\
\hline Simple & 7.76 & 0.73 & Compuesta & 7.70 & 1.02 \\
\hline (Sujeto) & 7.76 & 0.77 & (Objeto) & 7.70 & 0.93 \\
\hline Media Total $=15.46(1.58)$ & & \\
\hline
\end{tabular}

Por su parte, los análisis para valorar la normalidad de la distribución muestral, así como los índices de fiabilidad, dificultad y homogeneidad de las pruebas, se muestran en la Tabla 3. Debido a la ausencia de normalidad en las puntuaciones correspondientes a la tarea de comprensión, diversos análisis posteriores fueron realizados con pruebas no paramétricas. Con relación al Índice de Dificultad Medio (IDM), calculado a raíz del porcentaje promedio de estudiantes que falla cada ítem, debemos señalar que el indicador obtenido en la tarea CS-ORD se ajusta a los niveles considerados óptimos (entre .40 y .60); sin embargo, no ocurre así para la tarea de comprensión, en la que el IDM revela la escasa dificultad que habría supuesto esta tarea. Por su parte, el Índice Medio de Homogeneidad (IMH), indicador del nivel promedio de correlación existente entre cada ítem y la puntuación total, arroja resultados aceptables en ambos casos, superando el nivel crítico de .30 (Català, Català, Molina \& Monclús, 2001). En cuanto al índice de confiabilidad, los análisis muestran un valor aceptable para la tarea de comprensión, pero moderado para la tarea CS-ORD. En este sentido, si bien este último valor no se aleja de otros obtenidos con tareas similares en cuanto a número de ítems y contenido (Cain, 2007), requiere analizar la composición de la tarea en relación a la dificultad generalizada y escasa variabilidad que habrían presentado algunos de los ítems. Por último, debemos destacar la ausencia en ambas tareas de diferencias significativas entre las puntuaciones de los estudiantes de $5^{\circ}$ y $6^{\circ}$ curso, tanto en la puntuación total como en las distintas condiciones contrastadas; es por ello que los datos que se presentan corresponden al total de la muestra. 
Tabla 3. Indicadores estadísticos de validación para las tareas CS-ORD y comprensión de oraciones.

\begin{tabular}{|l|l|l|}
\hline Indicadores & Tarea CS-ORD & Tarea de comprensión \\
\hline Muestra & \multicolumn{2}{|c|}{$N=97$} \\
\hline Aplicación & \multicolumn{2}{|c|}{$5^{\circ}$ y $6^{\circ}$ primaria } \\
\hline Número de ítems & 24 & 16 \\
\hline Índice de Dificultad medio (IDM) & .58 & .04 \\
\hline Índice medio de Homogeneidad (IMH) & $.31(17$ correlaciones $\geq .25)$ & $.55(14$ correlaciones $\geq .25)$ \\
\hline $\begin{array}{l}\text { Prueba «Kolmogorov-Smirnov» de normali- } \\
\text { dad* }\end{array}$ & $1.018(p<.251)$ & $3.698(p<.000)$ \\
\hline Fiabilidad (Alfa de Cronbach) & .62 & .85 \\
\hline
\end{tabular}

Nota: La distribución se ajusta a la normalidad en la tarea CS-ORD, pero no en el caso de la tarea de comprensión de oraciones.

\subsection{Resultados obtenidos en función de los objetivos e hipótesis planteadas}

Objetivo (1), hipótesis 1: Las oraciones semánticamente inverosímiles supondrán una mayor dificultad lectora para los estudiantes en comparación con las verosímiles.

Con el objetivo de contrastar nuestra primera hipótesis, hemos efectuado diversos análisis que nos permitirán valorar el grado relativo de dificultad asociado al procesamiento de oraciones semánticamente inverosímiles frente a las verosímiles, así como valorar esta misma dificultad en relación a cada una de las demás condiciones contempladas. En la Tabla 4 mostramos los contrastes efectuados con la prueba $t$ para muestras relacionadas para la tarea CS-ORD en el grupo completo. Hemos contemplado en relación a la verosimilitud (verosímil-inverosímil), las condiciones de longitud (corta-larga) y complejidad sintáctica (simple-compuesta; coordinadasubordinada). Los resultados confirman nuestra primera hipótesis, mostrando que la condición inverosímil ha representado una dificultad significativamente mayor con relación a las oraciones semánticamente verosímiles $\left(t_{(2,96)}=13.78, p<.000\right)$. Asimismo, los datos muestran diferencias significativas cuando contrastamos esta condición en relación a las oraciones largas, simples, compuestas, coordinadas y subordinadas. 
Tabla 4. Condiciones contempladas en la tarea CS-ORD y contrastes efectuados con la prueba t para muestras relacionadas $(N=97)$.

\begin{tabular}{|l|l|}
\hline Condiciones y contrastes efectuados para la tarea CS-ORD & $\begin{array}{l}\text { Prueba } \boldsymbol{t} \text { para } \\
\text { muestras } \\
\text { relacionadas }\end{array}$ \\
\hline Simple Corta Verosímil - Simple Corta Inverosímil (Corta V-Corta I) & 0.00 \\
\hline Simple Larga Verosímil - Simple Larga Inverosímil (Larga V-Larga I) & $8.82^{* * *}$ \\
\hline $\begin{array}{l}\text { Compuesta Coordinada Verosímil - Compuesta Coordinada Inverosímil (Coord. V - } \\
\text { Coord. I) }\end{array}$ & $4.44^{* * *}$ \\
\hline $\begin{array}{l}\text { Compuesta Subordinada Verosímil - Compuesta Subordinada Inverosímil (Sub. V - } \\
\text { Sub. I) }\end{array}$ & $9.84^{* * *}$ \\
\hline Simple Verosímil - Simple Inverosímil (Simple V - Simple I) & $8.96^{* * *}$ \\
\hline Compuesta Verosímil - Compuesta Inverosímil (Comp. V - Comp. I) & $10.00^{* * *}$ \\
\hline Total Verosímil - Total Inverosímil (V - I) & $13.78^{* * *}$ \\
\hline
\end{tabular}

Nota: Los contrastes con signo negativo expresan diferencias favorables a la segunda condición; ${ }^{*} p<.05 ;{ }^{* *} p<.01 ;{ }^{* *} p<.001$.

Objetivo (1), hipótesis 2: La condición verosimilitud tendrá un mayor peso que la complejidad sintáctica y la longitud a la hora de explicar los resultados y las dificultades encontradas.

Nuestra segunda hipótesis argumenta que la condición de verosimilitud tendrá un mayor peso en la explicación de los resultados, que la longitud o la complejidad sintáctica. Hemos realizado un análisis de varianza utilizando como variable dependiente la suma de las puntuaciones obtenidas en cada uno de los ítems y como factores las condiciones de longitud, complejidad sintáctica y verosimilitud. Debido a que en la tarea de ordenación de frases hay un mayor número de oraciones largas y de oraciones subordinadas, hemos seleccionado de las 8 oraciones largas, 4 equivalentes a las frases cortas en cuanto al resto de condiciones; del mismo modo, para el contraste entre oraciones coordinadas y subordinadas, hemos seleccionado 4 subordinadas equivalentes a las coordinadas en el resto de condiciones contempladas. En la Tabla 5 recogemos los estadísticos descriptivos correspondientes a los promedios y desviaciones típicas obtenidos en las distintas condiciones en esta tarea. En los análisis efectuados, observamos un efecto de la longitud $\left(F_{(1,8)}=439.19, p<.000, \eta^{2}\right.$ parcial $=.99)$, reflejando una mayor facilidad de las oraciones cortas, así como de la verosimilitud, reflejando a su vez la mayor facilidad de las oraciones semánticamente verosímiles $\left(F_{(1,8)}=85.63, p<.001, \eta^{2}\right.$ parcial $\left.=.95\right)$; asimismo, los datos muestran un efecto de la interacción Longitud $*$ Verosimilitud $\left(F_{(1,8)}=85.63, p<.001, \eta^{2}\right.$ parcial $=$ .95). De este modo, encontramos mayores diferencias entre oraciones cortas y largas inverosímiles que entre oraciones cortas y largas verosímiles, llegando esta diferencia a ser significativa $\left(t_{(2,96)}=7.37, p<.000\right)$, aunque en ambos casos las diferencias son a su vez significativas $\left(t_{(2,96)}=14.26, p<.000, y_{(2,96)}=6.61, p<.000\right.$, respectivamente). 
Tabla 5. Estadísticos descriptivos correspondientes a las puntuaciones promedio obtenidas en cada una de las condiciones contempladas en la tarea de ordenación de frases

(CS-ORD).

\begin{tabular}{|c|c|c|c|c|c|c|}
\hline \multicolumn{3}{|l|}{ Condiciones } & Media $(D T)$ & Total $(D T)$ & Media V $(D T)$ & Media I (DT) \\
\hline \multirow{4}{*}{$\begin{array}{l}\text { Longitud } \\
\text { V-I }\end{array}$} & \multirow{2}{*}{ Corta } & V & $95.00(2.83)$ & \multirow{2}{*}{$95.00(1.83)$} & \multirow{4}{*}{$84.25(12.58)$} & \multirow{4}{*}{$67.25(32.12)$} \\
\hline & & I & 95.00 (1.41) & & & \\
\hline & \multirow{2}{*}{ Larga } & V & $73.50(2.12)$ & \multirow{2}{*}{$56,50(19.77)$} & & \\
\hline & & I & 39.50 (3.54) & & & \\
\hline \multirow{4}{*}{$\begin{array}{l}\text { Simple-Comp. } \\
\text { V-I }\end{array}$} & \multirow{2}{*}{ Simple } & V & $80.33(11.69)$ & \multirow{2}{*}{$71.92(21.04)$} & \multirow{4}{*}{$52.50(32.37)$} & \multirow{4}{*}{$34.42(35.33)$} \\
\hline & & I & $63.50(25.83)$ & & & \\
\hline & \multirow{2}{*}{ Compuesta } & V & $24.67(17.59)$ & \multirow{2}{*}{$15.00(16.28)$} & & \\
\hline & & I & $5.33(7.01)$ & & & \\
\hline \multirow{4}{*}{$\begin{array}{l}\text { Activa-Pasiva } \\
\text { V-I }\end{array}$} & \multirow{2}{*}{ Activa } & V & $73.50(2.12)$ & \multirow{2}{*}{$56.50(19.77)$} & \multirow{4}{*}{$73.00(3.16)$} & \multirow{4}{*}{47.75 (10.91) } \\
\hline & & I & $39.50(3.54)$ & & & \\
\hline & \multirow{2}{*}{ Pasiva } & V & $72.50(4.95)$ & \multirow{2}{*}{$64.25(11.09)$} & & \\
\hline & & I & $56.00(8.49)$ & & & \\
\hline \multirow{4}{*}{$\begin{array}{l}\text { Coord.-Sub- } \\
\text { ord. } \\
\text { V-I }\end{array}$} & \multirow{2}{*}{ Coordinada } & V & $27.00(1.41)$ & \multirow{2}{*}{$18.50(12.29)$} & \multirow{4}{*}{33.25 (13.89) } & \multirow{4}{*}{$6.75(8.50)$} \\
\hline & & I & $10.00(12.73)$ & & & \\
\hline & \multirow{2}{*}{ Subordinada } & $\mathrm{V}$ & $39.50(20.51)$ & \multirow{2}{*}{$21.50(24.01)$} & & \\
\hline & & I & $3.50(3.54)$ & & & \\
\hline
\end{tabular}

Nota: La puntuación máxima que es posible alcanzar en cada uno de los ítems coincide con el número de sujetos de la muestra (97); V = verosímil; I = inverosímil.

Observamos también un efecto significativo de la Complejidad-SC (simplecompuesta) $\left(F_{(1,24)}=66.89, p<.000, \eta^{2}\right.$ parcial $\left.=.77\right)$, mostrando la mayor facilidad de las oraciones simples sobre las compuestas (en estos contrastes no se asumieron varianzas iguales, $p<.05)$. Asimismo, encontramos un efecto de la condición Verosimilitud ( $F_{(1,}$ 24) $=6.75, p<.017, \eta^{2}$ parcial $\left.=.25\right)$; sin embargo, en esta ocasión no hallamos efecto de la interacción Complejidad-SC*Verosimilitud $\left(F_{(1,24)}=.032, p<.86, \eta^{2}\right.$ parcial $=$ .002). En este caso, las diferencias entre oraciones verosímiles simples y compuestas son tan importantes como las diferencias entre oraciones inverosímiles simples y compuestas. Por su parte, en los contrastes relativos a las oraciones activas y pasivas, no hemos encontrado efecto principal de la Complejidad-AP (Activa-Pasiva) $\left(F_{(1,8)}=\right.$ $4.23, p<.109, \eta^{2}$ parcial $\left.=.51\right)$ y solo hallamos un efecto significativo de la condición Verosimilitud $\left(F_{(1,8}=44.94, p<.003, \eta^{2}\right.$ parcial $\left.=.92\right)$. Tampoco encontramos en este caso un efecto significativo de la interacción Complejidad-AP*Verosimilitud $\left(F_{(1,8)}=\right.$ $5.40, p<.081, \eta^{2}$ parcial $\left.=.57\right)$. Los datos revelan que no existen diferencias reseñables entre las puntuaciones obtenidas en las oraciones verosímiles activas y pasivas, y que entre las inverosímiles, aquellas que obtienen mejor puntuación son sorpresivamente las pasivas. A pesar de no ser significativos, estos datos sugieren que las dificultades propias de esta tarea, unidas a las mayores exigencias de procesamiento sintáctico en 
las oraciones inverosímiles, habrían llegado a solapar las diferencias habituales entre oraciones activas y pasivas. Por último, tampoco observamos efecto significativo de la condición Complejidad-CS (Coordinada-Subordinada) $\left(F_{(18)}=.12, p<.75, \eta^{2}\right.$ parcial $=.03), y$, al igual que en el caso anterior, sí hallamos efecto de la condición Verosimilitud $\left(F_{(1,8)}=9.41, p<.037, \eta^{2}\right.$ parcial $\left.=.70\right)$. Asimismo, para este contraste, tampoco hallamos efecto de la interacción Complejidad-CS*Verosimilitud. En este caso, la condición verosimilitud también habría representado una dificultad más significativa para el resultado final que la distinción entre oraciones coordinadas y subordinadas. En síntesis, los datos obtenidos de los análisis de varianza confirman nuestra segunda hipótesis, por cuanto la condición verosimilitud habría mostrado un mayor peso que el resto de condiciones en la explicación de los resultados obtenidos.

Objetivo (2), hipótesis 3: Los lectores con un perfil 'sintáctico' puntuarán mejor en comprensión que los de perfil 'semántico' y ambos tipos de lectores superarán a los lectores 'anómalos'.

La tercera de nuestras hipótesis predecía que aquellos lectores con altas puntuaciones tanto en ítems de contenido inverosímil (y que por tanto exigen la aplicación de estrategias sintácticas), como en los de contenido verosímil, obtendrían mayores puntuaciones en comprensión que los lectores con bajas puntuaciones en ítems inverosímiles, aunque hubieran obtenido buenos resultados en los de contenido verosímil. Para contrastar esta hipótesis, en primer lugar hemos establecido dos grupos en función de su nivel de comprensión y hemos examinado sus puntuaciones en la tarea CS-ORD. Posteriormente, hemos configurado distintos perfiles lectores en función de las estrategias empleadas en la resolución de la tarea y hemos procedido a su distribución en los dos grupos de nivel de comprensión. Esperábamos encontrar que los lectores con un perfil más sintáctico tuvieran mayor puntuación en comprensión que el resto.

Para dividir la muestra en función del nivel de comprensión, hemos utilizado la puntuación mediana (15.72) con el fin de establecer dos subgrupos (Cerdán, Gilabert \& Vidal-Abarca, 2010). El primer subgrupo está compuesto por aquellos estudiantes con mejor nivel de comprensión (MNC), que se sitúan por encima del percentil 50 (N $=72 ; M=16.00, D T=0.00)$; el segundo subgrupo está compuesto por los estudiantes con percentil $\leq 50(N=25 ; M=13.92, D T=2.57)$ y que por tanto presentan peor nivel de comprensión (PNC). El contraste de medias entre estos grupos, efectuado con la prueba 'U de Mann-Whitney', es significativo $(Z=9.71, p<.000)$. Una vez dividida la muestra, previo a establecer los perfiles lectores, hemos querido saber en qué medida las distintas condiciones contempladas en CS-ORD, especialmente la distinción realizada entre oraciones verosímiles e inverosímiles, se refleja en las puntuaciones de cada subgrupo en la tarea de comprensión; es decir, si las distintas condiciones afectan de igual manera a los estudiantes con mejor y peor nivel de comprensión. En la Tabla 6 mostramos los contrastes efectuados en función del nivel de comprensión; los análisis han sido efectuados con la prueba $t$ para muestras 
relacionadas y con la prueba de 'Wilcoxon'. Además de la condición verosimilitud (verosímil-inverosímil), hemos contemplado las condiciones de longitud (corta-larga) y complejidad estructural o sintáctica (activa-pasiva, simple-compuesta y coordinadasubordinada).

Tabla 6. Estadísticos y contrastes en función del nivel de comprensión para cada una de las condiciones contempladas.

\begin{tabular}{|c|c|c|c|c|}
\hline Condiciones & $\begin{array}{c}\text { MNC }(N=72) \\
\text { Media }(D T)\end{array}$ & $\begin{array}{l}\text { Contrastes MNC } \\
(N=72) \text { Prueba } t\end{array}$ & $\begin{array}{c}\text { PNC }(N=25) \\
\text { Media }(D T)\end{array}$ & $\begin{array}{l}\text { Contrastes PNC } \\
(N=25) \text { Prueba } t\end{array}$ \\
\hline $\begin{array}{l}\text { Corta } \\
\text { Larga }\end{array}$ & $\begin{array}{l}3.92(0.40) \\
2.44(1.17)\end{array}$ & $9.95^{* * *}$ & $\begin{array}{l}3.92(0.40) \\
2.36(0.86)\end{array}$ & $8.51 * * *$ \\
\hline $\begin{array}{l}\text { Corta V } \\
\text { Corta I }\end{array}$ & $\begin{array}{l}1.96(0.20) \\
1.96(0.26)\end{array}$ & 0.00 & $\begin{array}{l}1.96(0.20) \\
1.96(0.20)\end{array}$ & 0.00 \\
\hline $\begin{array}{l}\text { Larga V } \\
\text { Larga I }\end{array}$ & $\begin{array}{l}3.04(0.88) \\
2.03(1.19)\end{array}$ & $7.77 * * *$ & $\begin{array}{l}2.92(1.15) \\
1.80(0.96)\end{array}$ & $4.20^{* * *}$ \\
\hline $\begin{array}{l}\text { Activa } \\
\text { Pasiva }\end{array}$ & $\begin{array}{l}2.42(1.11) \\
2.65(1.10)\end{array}$ & -1.51 & $\begin{array}{l}2.08(0.99) \\
2.64(0.86)\end{array}$ & $-3.22^{* *}$ \\
\hline $\begin{array}{l}\text { Simple } \\
\text { Compuesta }\end{array}$ & $\begin{array}{l}8.99(1.87) \\
2.01(1.48)\end{array}$ & $28.98^{* * *}$ & $\begin{array}{l}8.64(1.82) \\
1.40(1.53)\end{array}$ & $4.40 * * *$ \\
\hline $\begin{array}{l}\text { Simple V } \\
\text { Simple I }\end{array}$ & $\begin{array}{l}5.00(0.89) \\
3.99(1.24)\end{array}$ & $7.96^{* * *}$ & $\begin{array}{l}4.88(1.24) \\
3.76(1.01)\end{array}$ & $4.20 * * *$ \\
\hline $\begin{array}{l}\text { Compuesta V } \\
\text { Compuesta I }\end{array}$ & $\begin{array}{l}1.67(1.21) \\
0.35(0.59)\end{array}$ & $9.36^{* * *}$ & $\begin{array}{l}1.12(1.13) \\
0.28(0.68)\end{array}$ & $3.93 * * *$ \\
\hline $\begin{array}{l}\text { Coordinada } \\
\text { Subordinada }\end{array}$ & $\begin{array}{l}0.79(0.82) \\
1.03(0.89)\end{array}$ & -1.85 & $\begin{array}{l}0.68(0.95) \\
0.60(0.82)\end{array}$ & 0.46 \\
\hline $\begin{array}{l}\text { Coordinada V } \\
\text { Coordinada I }\end{array}$ & $\begin{array}{l}0.58(0.71) \\
0.21(0.41)\end{array}$ & $3.92 * * *$ & $\begin{array}{l}0.48(0.71) \\
0.20(0.41)\end{array}$ & $2.06^{*}$ \\
\hline $\begin{array}{l}\text { Subordinada V } \\
\text { Subordinada I }\end{array}$ & $\begin{array}{l}1.08(0.88) \\
0.14(0.39)\end{array}$ & $9.38^{* * *}$ & $\begin{array}{l}0.64(0.70) \\
0.08(0.40)\end{array}$ & $3.65^{* * *}$ \\
\hline $\begin{array}{l}\text { Total V } \\
\text { Total I }\end{array}$ & $\begin{array}{l}6.67(1.60) \\
4.33(1.46)\end{array}$ & $13.19 * * *$ & $\begin{array}{l}6.00(2.06) \\
4.04(1.27)\end{array}$ & $3.80 * * *$ \\
\hline
\end{tabular}

Nota: $\mathrm{MNC}=$ mejor nivel de comprensión $; \mathrm{PNC}=$ peor nivel de comprensión $; \mathrm{V}=$ Verosímil; I = Inverosímil. En el subgrupo PNC, para los contrastes V-I y Simple-Compuesta se ha utilizado la prueba de Wilcoxon debido a la ausencia de normalidad en la distribución muestral para las condiciones V, I y Simple. Los contrastes con signo negativo expresan diferencias favorables a la segunda condición; ${ }^{*} p<.05 ;{ }^{* *} p<.01 ;{ }^{* * *} p<.001$. 
Los resultados muestran que la condición inverosímil ha representado una dificultad significativamente mayor que la condición verosímil en los dos subgrupos compuestos en función del nivel de comprensión. Asimismo, los datos muestran diferencias significativas cuando contrastamos esta condición en relación a las oraciones largas, simples, compuestas, coordinadas y subordinadas. Debemos destacar que las diferencias de medias entre las condiciones V-I no son mayores para el grupo de peor nivel, mostrando éste puntuaciones más bajas con respecto al grupo MNC tanto en oraciones verosímiles como inverosímiles. Hemos contrastado también las puntuaciones obtenidas por ambos grupos en los ítems de contenido inverosímil en cada una de las condiciones contempladas. Estos contrastes podrían revelar si el grupo MNC obtiene mejores resultados en estos ítems que el grupo de peor nivel. Como podemos observar en la Tabla 6, los datos muestran en todos los casos que las puntuaciones obtenidas en la condición inverosímil por el grupo MNC son mayores que las del grupo PNC, aunque estas diferencias no llegan a ser significativas en ninguno de los contrastes efectuados. En definitiva, estos resultados no relacionarían significativamente el nivel de comprensión de oraciones con el uso de habilidades específicas de procesamiento sintáctico.

A continuación, con objeto de establecer los diferentes perfiles lectores, hemos obtenido las puntuaciones de los ítems de la condición verosímil de la tarea CSORD y asimismo las puntuaciones correspondientes a la condición inverosímil. Estas puntuaciones difieren significativamente a favor de las primeras (Media ítems verosímiles $=6.49(1.75) ;$ Media ítems inverosímiles $=4.26(1.42),\left(t_{(2,96)}=\right.$ $13.78, p<.000)$. Posteriormente, hemos procedido a efectuar un conglomerado de $\mathrm{K}$ medias. Esta prueba maximiza las diferencias entre los casos, agrupándolos en conglomerados o clusters que comparten patrones de respuesta similares. Hemos utilizado las puntuaciones obtenidas en los ítems verosímiles e inverosímiles de la tarea CS-ORD como criterio para la configuración de estos clusters. Los análisis dan como resultado tres grupos, alcanzando la máxima distancia entre los centros de estos conglomerados después de 4 iteraciones. De este modo, a partir de los datos obtenidos se han establecido tres perfiles: uno denominado 'Lectores sintácticos', con puntuaciones altas tanto en los ítems inverosímiles como en los verosímiles; un segundo subgrupo que hemos denominado 'Lectores semánticos', con puntuaciones altas en los ítems verosímiles pero bajas en los inverosímiles; y por último, un grupo de 'Lectores anómalos', compuesto por aquellos estudiantes que puntuaron bajo en los dos tipos de ítems. Los resultados se recogen en la Tabla 7. 
Tabla 7. Perfiles lectores en función de las puntuaciones obtenidas en los ítems verosímiles e inverosímiles de la tarea CS-ORD y distribución en función del nivel de comprensión.

\begin{tabular}{|c|c|c|c|c|c|c|c|c|}
\hline \multirow{2}{*}{$\begin{array}{l}\text { Perfiles } \\
\text { lectores }\end{array}$} & \multirow{2}{*}{$N$} & \multirow{2}{*}{$\begin{array}{l}M(D T) \\
\text { ítems } \\
\text { vero- } \\
\text { símiles }\end{array}$} & \multirow{2}{*}{$\begin{array}{l}M(D T) \\
\text { ítems in- } \\
\text { verosímiles }\end{array}$} & \multirow{2}{*}{$\begin{array}{l}\text { Tarea de } \\
\text { Comprensión }\end{array}$} & \multicolumn{4}{|c|}{$\begin{array}{l}\text { Distribución en función del nivel de } \\
\text { comprensión }\end{array}$} \\
\hline & & & & & $\% \mathrm{~N}$ & C $M(D T)$ & $\% \mathrm{P}$ & C $M(D T)$ \\
\hline $\begin{array}{l}\text { Lectores } \\
\text { 'sintácticos' }\end{array}$ & 17 & $8.47(0.29)$ & $6.29(0.24)$ & $15.82(0.39)$ & 82.4 & $16.00(0.00)$ & 17.6 & $15.00(0.00)$ \\
\hline $\begin{array}{l}\text { Lectores } \\
\text { 'anómalos' }\end{array}$ & 30 & $4.47(0.17)$ & $3.23(0.18)$ & $14.73(2.64)$ & 60 & $16.00(0.00)$ & 40 & $12.83(3.43)$ \\
\hline 'sectores & 50 & $7.04(0.13)$ & $4.18(0.14)$ & $15.78(0.47)$ & 80 & $16.00(0.00)$ & 20 & $14.90(0.32)$ \\
\hline
\end{tabular}

Nota: $\mathrm{MNC}=$ mejor nivel de comprensión $; \mathrm{PNC}=$ peor nivel de comprensión; $\%$ = porcentaje de sujetos en cada categoría.

Los análisis para contrastar las posibles diferencias en comprensión entre los distintos perfiles han sido efectuados con la prueba $t$ para muestras independientes (sin asumir varianzas iguales) y con la prueba no paramétrica ' $U$ de Mann-Whitney' Los datos no muestran diferencias entre lectores sintácticos y semánticos con relación al nivel de comprensión. En cambio, si revelan diferencias significativas entre lectores sintácticos y anómalos $\left(t_{(2,31.23)}=2.22, p<.034\right)$, y asimismo, entre semánticos y anómalos $\left(t_{(2,30.08)}=2.15, p<.039\right)$. Aunque la prueba utilizada es robusta, hemos efectuado estos mismos contrastes con la prueba no paramétrica debido a la ausencia de normalidad en las puntuaciones de origen. En este caso, los datos muestran solo diferencias marginales entre lectores sintácticos y anómalos (' $U$ de Mann-Whitney' $=-1.78, p<.076$ ), mientras que siguen señalando diferencias significativas entre semánticos y anómalos ('U de Mann-Whitney' $=-2.23, p<.025$ ). No hallamos, al igual que antes, diferencias entre lectores sintácticos y semánticos. Por otra parte, la distribución porcentual de los perfiles lectores en función de su nivel de comprensión no refleja diferencias reseñables entre lectores sintácticos y semánticos, situándose en ambos casos en torno al 80\% de alumnos en el subgrupo de mejor nivel; por su parte, las diferencias con relación a los lectores anómalos se sitúan en 20 puntos porcentuales, a pesar de lo cual el $60 \%$ de estos alumnos fue clasificado en el subgrupo MNC. En síntesis, estos resultados no apoyarían nuestra tercera hipótesis, por cuanto nuestros datos no nos permiten asegurar que los estudiantes con un perfil sintáctico obtengan mejores puntuaciones en comprensión que aquellos estudiantes que han mostrado un perfil más semántico. Es posible que las altas puntuaciones generalizadas en la medida de comprensión, hayan tenido un peso notable en estos resultados, dificultando la discriminación adecuada entre perfiles lectores en relación a su rendimiento en comprensión. 
Objetivo (3), hipótesis 4: Los ítems con mayor carga de procesamiento semántico (contenido verosímil) presentarán una mayor relación con el nivel de comprensión que los ítems con contenido inverosímil.

Por último, hemos efectuado análisis de correlación no paramétrica mediante la prueba Tau_b de Kendall, con el objetivo de valorar en qué medida el conjunto de ítems de la condición verosímil de la tarea CS-ORD muestra un mayor índice de correlación con la medida de comprensión que aquellos ítems de la condición inverosímil, más dependientes de un procesamiento exclusivamente sintáctico. En este sentido, como apuntábamos anteriormente, la ejecución de la tarea CS-ORD en su condición verosímil, puede verse facilitada por la aplicación de estrategias de procesamiento semántico basadas en el conocimiento previo del estudiante acerca del significado de las palabras y de la relación lógica que suele haber entre ellas. Los datos expuestos en este estudio muestran con claridad que los ítems verosímiles resultaron más fáciles para los estudiantes que aquellos con contenido inverosímil. Esta diferencia en la ejecución induce a pensar que en la resolución de las frases verosímiles los estudiantes habrían utilizado no solo estrategias sintácticas para resolver la tarea, sino también estrategias de procesamiento semántico que habrían facilitado la ordenación de los elementos en función de los aspectos anteriormente citados. De este modo, la tipología de ítems utilizados en tareas de CS, podría condicionar la relación existente con el nivel de comprensión (Cain, 2007).

Los resultados de los análisis muestran que la puntuación en comprensión mantiene una correlación significativa con la parte de la tarea CS-ORD que tiene una mayor carga semántica $(r(97)=.151, p<.042)$, situándose en el límite de la significación estadística con relación a la tarea completa $(r(97)=.139, p<.052)$. En cambio, aunque positiva, no llega a ser significativa la correlación que mantiene con la condición inverosímil de esta tarea $(r(97)=.158, p<.089)$. El análisis de regresión ordinal muestra que solo la condición verosímil de la tarea establece una relación significativa con la comprensión (Pseudo $R^{2}$ Cox y Snell = .29; 'Chi-Cuadrado' $=32.93$, $p<.008$ ). Este dato, que confirmaría nuestra hipótesis y los resultados obtenidos por Cain (2007) utilizando una prueba oral de ordenación de frases, sugiere que la tipología de ítems podría influir decisivamente en la relación establecida entre CS y comprensión. De este modo, al menos en parte, la resolución de la tarea CS-ORD podría realizarse aplicando estrategias de procesamiento semántico, lo que sugiere la relevancia de considerar en esta tarea oraciones semánticamente inverosímiles con el fin de aislar el componente sintáctico. Por otra parte, los datos también sugieren una cierta independencia entre factores sintácticos y semánticos en la resolución de las tareas, lo que podría traducirse en que las habilidades de procesamiento sintáctico 'aisladas' tendrían una incidencia limitada en el nivel de comprensión. No obstante, debemos reseñar que la correlación entre las dos partes (verosímil e inverosímil) de la tarea es significativa, aunque moderada $(r(97)=.388, p<.000)$, lo que atenuaría en parte la independencia apuntada anteriormente, dejando entrever una mayor interdependencia entre ambos factores. 


\section{Discusión y conclusiones}

El principal objetivo del estudio presentado consistía en comprobar en qué medida el grado de verosimilitud en el contenido de frases desordenadas afectaba a la tarea de estructurar correctamente estas frases, y de qué modo esto se relacionaba con el nivel de comprensión de oraciones. Con este propósito planteamos tres objetivos específicos, en relación a los cuales se formularon cuatro hipótesis de trabajo. Con el primero de los objetivos pretendíamos comprobar si efectivamente las frases desordenadas con contenido inverosímil representaban una mayor dificultad para los estudiantes a la hora de ordenarlas, en comparación con las verosímiles. Asimismo, queríamos analizar comparativamente la relevancia de la condición verosimilitud con relación a la longitud de las frases o a la estructura gramatical. Por otra parte, en relación al segundo objetivo, pretendíamos establecer distintos perfiles lectores en función de la relación entre las puntuaciones obtenidas en los ítems de contenido verosímil e inverosímil, y evaluar su correspondencia con el nivel de comprensión de oraciones. Por último, nuestro tercer objetivo planteaba la necesidad de comprobar de qué modo la tipología de ítems utilizada en la tarea CS-ORD (verosímil-inverosímil) podría condicionar la relación entre CS y nivel de comprensión.

En relación al primer objetivo, los datos obtenidos confirman nuestra primera hipótesis, por cuanto la condición inverosímil, representada por frases con una estructura sintáctica correcta pero semánticamente inverosímiles, ha supuesto un grado de dificultad de procesamiento significativamente mayor para los estudiantes en comparación con la condición representada por las oraciones verosímiles. Estos resultados son congruentes con estudios previos, tanto en relación a los obtenidos con tareas de ordenación de frases desordenadas (Cain, 2007), como en relación a los obtenidos con otras tareas de evaluación de la CS (Miller, 2010).

En nuestra segunda hipótesis, relacionada también con el primer objetivo, predecíamos que la condición verosimilitud, entendida como el grado de exigencia en el uso de estrategias sintácticas para resolver la tarea, representaría el factor más decisivo en la explicación de los resultados. En este sentido, los datos confirman que el procesamiento de oraciones semánticamente inverosímiles habría representado una dificultad significativa en todos los contrastes efectuados entre las distintas condiciones contempladas. De este modo, si bien la distinción relativa a la longitud establece diferencias significativas de partida, estas diferencias se incrementan y se explican en definitiva por la entrada en juego de unas mayores exigencias sintácticas. Asimismo, no observamos efectos independientes de las estructuras activa-pasiva y coordinada-subordinada; sin embargo sí encontramos efectos significativos de la dificultad de las oraciones compuestas sobre las de estructura simple. En resumen, habrían sido las oraciones compuestas, por una parte, y todas aquellas con mayores requerimientos de procesamiento sintáctico (inverosímiles), las que finalmente han supuesto mayores dificultades. En general, la condición verosimilitud ha constituido 
un factor decisivo en la explicación de los resultados, bien como factor independiente o bien en interacción con otros factores relativos a la longitud o la estructura gramatical. De este modo, los análisis efectuados confirman en buena medida la hipótesis formulada.

En relación al segundo objetivo planteado, los datos no confirman, en cambio, la tercera de nuestras hipótesis. Los estudiantes con un perfil lector 'sintáctico' no obtienen mejores resultados en comprensión que aquellos que presentan un perfil 'semántico'. Sin embargo, sí hemos podido constatar que tanto unos como otros obtienen significativamente mejores puntuaciones en comprensión que el grupo de lectores 'anómalos'. Asimismo, entre los lectores sintácticos, más del 80\% de sus integrantes fueron clasificados en el grupo de mejor nivel de comprensión, aunque no se establecieron diferencias notables con el porcentaje de lectores semánticos que también integró este grupo. Estos resultados son relativamente similares a los obtenidos por Miller (2010) con estudiantes de tercer y cuarto curso de primaria. En su caso, el 85\% de los lectores sintácticos y entre el $67 \%$ y el $89 \%$ de los lectores semánticos, se situaba con altas puntuaciones en comprensión, mientras que el $60 \%$ de los que obtenían bajas puntuaciones en comprensión eran lectores anómalos (en nuestro caso, solo el 40\%). No obstante, debemos señalar que el tipo de tarea utilizada por Miller (2010), similar a la utilizada por nosotros como medida de comprensión, aunque incluyendo frases inverosímiles, difiere notablemente del que exponemos aquí. Esto parece poner de manifiesto, como apuntábamos en la introducción, que el uso de tareas diferenciadas para valorar distintos aspectos de la CS, podría explicar la obtención de resultados desiguales a la hora de relacionar CS y comprensión.

Asimismo, no podemos confirmar que el grupo de alumnos con mejor nivel de comprensión obtenga significativamente mejores puntuaciones que el grupo de peor nivel en el conjunto de ítems que requerían esencialmente de un procesamiento sintáctico, e igual ocurre cuando realizamos los contrastes solo con los ítems de contenido semántico o con la puntuación total. En este sentido, la mayor dificultad constatada en los ítems inverosímiles se ha producido en los dos subgrupos conformados en función del nivel de comprensión, no produciéndose una mayor diferencia entre las dos condiciones en el grupo de peor nivel, es decir, este grupo ha obtenido peores resultados tanto en ítems verosímiles como inverosímiles. Esto sugiere que las dificultades de estos estudiantes no se situarían de modo específico en el procesamiento sintáctico, como así podría tener lugar en estudiantes con discapacidad auditiva (Miller, 2010). No obstante, algunos de estos resultados, así como los que muestran la relación entre perfiles lectores y nivel de comprensión, podrían haberse visto afectados por las altas puntuaciones generalizadas obtenidas en la tarea de comprensión. En efecto, las puntuaciones de esta tarea reflejan un cierto efecto 'techo', lo que habría dificultado una adecuada discriminación entre los integrantes de cada nivel, afectando a los contrastes para determinar la relación de los perfiles lectores con los niveles de comprensión. En definitiva, la ausencia 
de variabilidad suficiente en las puntuaciones de comprensión, habría constituido una limitación importante que debemos tener en cuenta a la hora de interpretar los resultados con relación a esta tercera hipótesis.

En cuanto a nuestra cuarta hipótesis, en relación al tercero de nuestros objetivos, hemos confirmado que aquellos ítems de la tarea CS-ORD que pueden ser resueltos en parte aplicando estrategias de procesamiento semántico, se relacionan significativamente con el nivel de comprensión (Cain, 2007), mientras que los ítems con mayor carga de procesamiento sintáctico no mantienen esta relación significativa -aunque sí parecen mostrar una tendencia a la significatividad. De este modo, los datos sugieren que el nivel de procesamiento sintáctico estaría solo parcialmente relacionado con el nivel de comprensión, manteniendo una cierta independencia en cuanto al nivel de logro en ambos procesos. Estos datos son congruentes con los obtenidos por Cain (2007) basados en tareas de aplicación oral y con una muestra de tamaño y edad similares. En la introducción señalábamos que este estudio mostraba cómo la aplicación de una estrategia de procesamiento sintáctico-semántico basada en el significado, acentuaba la relación entre CS y comprensión, y cómo en cambio las frases semánticamente reversibles, con mayor exigencia sintáctica, no mostraban esta relación significativa. Nuestros resultados vendrían también a confirmar que la tarea aplicada ofrecería información diferenciada en relación a los componentes sintáctico y semántico del lenguaje escrito. Esta información podría ser asimismo complementaria a la otorgada por otras tareas de procesamiento sintáctico más ligadas a los procesos semánticos (Miller, 2010), y podría concretarse en una mayor precisión para informar del uso de estrategias sintácticas sin relación directa con la comprensión, lo que podría ser especialmente útil a la hora de aislar este componente con objetivos de evaluación y análisis de posibles dificultades específicas.

Con relación a las limitaciones de este estudio, en la introducción hacíamos referencia a la posible mediación ejercida por variables como el conocimiento de estructuras gramaticales, el vocabulario o la memoria de trabajo en la relación existente entre CS y comprensión (Cain, 2007). Ya argumentamos que el hecho de plantear tareas escritas que el estudiante puede leer y releer durante su resolución, podía minimizar la influencia de la memoria de trabajo en comparación con tareas similares de aplicación oral. Asimismo, el hecho de que todas las palabras utilizadas en las frases fueran de alta frecuencia, ha permitido controlar en cierta medida el conocimiento y acceso al significado de las palabras que formaban parte de las tareas. En cambio, somos conscientes de que el mayor o menor conocimiento sobre las diversas estructuras gramaticales que se utilizan, podría haber constituido un factor relevante en la relación que se ha establecido entre CS y comprensión; en nuestro caso, el hecho de que la muestra estuviera compuesta por estudiantes de $5^{\circ}$ y $6^{\circ}$ curso pertenecientes a un mismo centro, puede haber contribuido a igualar el efecto de esta variable, sin que esto haya supuesto un control efectivo de este factor. Por tanto, debemos tener también esto en cuenta con respecto a la potencia de las conclusiones que es posible 
extraer. Por otra parte, ya hemos mencionado anteriormente la limitación que supone la ausencia de una mayor variabilidad en las puntuaciones obtenidas en la tarea de comprensión con relación a nuestra tercera hipótesis.

Finalmente, en relación a futuras vías de desarrollo y posibles implicaciones prácticas, entendemos que los resultados obtenidos permiten utilizar la tarea CSORD en estudios en los que poder comprobar cómo se comportan estudiantes con discapacidad auditiva, deprivación socio-cultural o dificultades específicas de aprendizaje. En este sentido, en sintonía con estudios precedentes (Bowey, 1986; Nation \& Snowling, 2000), hemos observado cómo los estudiantes con peor nivel de comprensión experimentan mayores dificultades en los ítems con mayor exigencia de procesamiento sintáctico. Aunque en nuestro estudio estos datos solo reflejan una tendencia, debido a las altas puntuaciones en comprensión obtenidas por ambos grupos, así como a la ausencia de dificultades específicas de aprendizaje, es de suponer que algunos de estos resultados se acentúen en casos en los que se presuponen mayores problemas precisamente en este tipo de procesos. Asimismo, el análisis diferenciado del contenido de la tarea aplicada y de los resultados obtenidos, nos ha permitido mostrar su distinta sensibilidad en su relación con la comprensión (Cain, 2007). El hecho de que los ítems de la condición inverosímil no hayan mostrado una relación directa con el nivel de comprensión, podría revelar que las dos partes de la tarea ofrecen información diferenciada y complementaria. En este sentido, la tarea en su conjunto informaría de la capacidad de manipular conscientemente los elementos gramaticales con el fin de ajustarlos a una estructura sintáctica correcta; sin embargo, mientras que los ítems de contenido inverosímil requieren que este proceso de manipulación y organización se realice con independencia del contenido, la condición verosímil presenta una conexión más transparente con la actividad lectora, basada en la relación lógica habitual entre los elementos, así como en los conocimientos previos del estudiante, mostrando un mayor grado de relación con el procesamiento semántico (Cain, 2007). Este aspecto nos parece especialmente importante, ya que puede contribuir a precisar la relevancia de distintos componentes de procesamiento sintáctico y semántico en la evaluación de la conciencia sintáctica y en su relación con la comprensión. 


\section{REFERENCIAS BIBLIOGRÁFICAS}

Alarcos, E. (2000). Gramática de la lengua española. Madrid: Espasa.

Andrés, M. L., Canet, L. \& García, A. (2010). Conciencia sintáctica en niños de 5 a 8 años de edad: Diseño de un instrumento y evaluación de sus propiedades psicométricas. Avaliação Psicológica, 9(2), 199-210.

Ball, E. W. (1997). Phonological awareness: Implications for whole language and emergent literacy programs. Topics in Language Disorders, 17, 14-26.

Bowey, J. A. (1986). Syntactic awareness in relation to reading skill and ongoing comprehension monitoring. Journal of Experimenal Child Psychology, 41, 282299.

Bowey, J. A. (1994). Grammatical awareness and learning to read: A critique. En E. M. H. Assink (Ed.), Literacy acquisition and social context (pp. 122-149). Londres: Harvester Wheatsheaf.

Bowey, J. A. \& Patel, R. K. (1988). Metalinguistic ability and early reading achievement. Applied Psycholinguistics, 9, 367-383.

Cain, K. (2007). Syntactic awareness and reading ability: Is there any evidence for a special relationship? Applied Psycholinguistics, 28, 679-694.

Català, G., Català, M., Molina, E. \& Monclús, R. (2001). Evaluación de la comprensión lectora. Barcelona: Graó.

Cerdán, R., Gilabert, R. \& Vidal-Abarca, E. (2010). Estrategias de selección de información en tareas de contestación a preguntas. Infancia y Aprendizaje, 33(4), 449-460.

Cuetos, F. (2008). Psicología de la lectura. Barcelona: Editorial Praxis.

Demont, E. \& Gombert, J. E. (1996). Phonological awareness as a predictor of recoding skills and syntactic awareness as a predictor of comprehension skills. British Journal of Educational Psychology, 66, 315-332.

Gombert, J. (1992). Metalinguistic development. Londres: Harvester Wheatsheaf.

Gombert, J. (1993). Metacognition, metalanguage and metapragmatics. International Journal of Psychology, 28(5), 571-580.

Gottardo, A., Stanovich, K. E. \& Siegel, L. (1996). The relationships between phonological sensitivity, syntactic processing, and verbal working memory in the reading performance of third-grade children. Journal of Experimental Child Psychology, 63, 563-582. 
Jiménez, J. E., Rodríguez, C., Guzmán, R. \& García, E. (2010). Desarrollo de los procesos cognitivos de la lectura en alumnos normolectores y alumnos con dificultades específicas de aprendizaje. Revista de Educación, 353, 361-386.

Layton, A., Robinson, J. \& Lawson, M. (1998). The relationship between syntactic awareness and reading performance. Journal of Research in Reading, 21(1), 5-23.

McCune, L. (2008). Review of Anat Ninio 'Language and the learning curve: A new theory of syntactic development'. Journal of Child Language, 35(4), 922-929.

Miller, P. (2010). Phonological, orthographic, and syntactic awareness and their relation to reading comprehension in prelingually deaf individuals: What can we learn from skilled readers? J Dev Phys Disabil, 22, 549-580.

Muter, V. \& Snowling, M. (1998). Concurrent and longitudinal predictors of reading: The role of metalinguistic and short-term memory skills. Reading Research Quarterly, 33, 320-337.

Nation, K. \& Snowling, M. J. (2000). Factors influencing syntactic awareness skills in normal readers and poor comprehenders. Applied Psycholinguistics, 21, 229-241.

Navarro, J. J. \& Rodríguez, I. R. (2011). Prueba de evaluación de la conciencia sintáctica (CSORD). Documento interno sin publicar.

Oakhill, J. V. \& Cain, K. (2005). Development of reading comprehension. En T. Nunes \& P. Bryant (Eds.), Handbook of Children's Literacy (pp. 155-180). Netherlands: Kluwer Academic Publishers.

Perfetti, C.A., Landi, N. \& Oakhill,J. (2005). The acquisition of reading comprehension skill. En M. J. Snowlling \& Ch. Hulme (Eds.), The science of reading. A bandbook (pp. 227-247). Oxford: Blackwell Publishing.

Rego, L. L. B. \& Bryant, P. E. (1993). The connection between phonological, syntactic and semantic skills and children's reading and spelling. European Journal of Psychology of Education, 8(3), 235-246.

Serrat, E., Sanz-Torrent, M., Badia, I., Aguilar, A., Olmo, R. \& Lara, F. (2010). La relación entre el aprendizaje léxico y el desarrollo gramatical. Infancia y Aprendiraje, 33(4), 435-448.

Sebastian, N., Martí, M. A. \& Carreiras, M. F. (2000). LEXESP: Léxico informatizado del español. Barcelona: Universidad de Barcelona.

Soriano, J., Pérez, I. \& Domínguez, A. (2006). Evaluación del uso de estrategias sintácticas en lectura por alumnos sordos con y sin implante coclear. Revista de Logopedia, Foniatría y Audiología, 26(2), 72-83. 
Tong, X., Deacon, H., Kirby, J., Cain, K. \& Parrila, R. (2011). Morphological awareness: A key to understanding poor reading comprehension in English. Journal of Educational Psychology, 103(3), 523-534.

Tunmer, W. E. (1989). The role of language-related factors in reading disability. En D. Shankweiler \& I. Y. Liberman (Eds.), Phonology and reading disability: Solving the reading puz:le (pp. 91-131). Ann Arbor, MI: University of Michigan Press.

Tunmer, W. \& Bowey, J. A. (1984). Metalinguistic awareness and reading acquisition. En W. E. Tunmer, C. Pratt \& M. L. Herriman (Eds.), Metalinguistic awareness in children: Theory, research and implications (pp. 144-168). Berlin: Springer-Verlag.

Tunmer, W. \& Herriman, M. (1984). The development of metalinguistic awareness: A conceptual overview. En W. Tunmer, C. Pratt \& M. L. Herriman (Eds.), Metalinguistic awareness in children (pp. 2-35). Berlín: Springer-Verlag.

Tunmer, W. \& Hoover, W. (1992). Cognitive and linguistic factors in learning to read. En P. B. Gough, L. C. Ehri \& R. Treiman (Eds.), Reading acquisition (pp. 175214). Hillsdale, NJ: Erlbaum.

Wigfield, A. \& Asher, S. R. (2002). Social and motivational influences on reading. En P. D. Pearson (Ed.), Handbook of reading research (pp. 423-452). Mahwah, NJ: Lawrence Erlbaum.

\section{* AGRADECIMIENTOS}

Esta investigación se pudo realizar gracias a la financiación recibida por la Consejería de Innovación, Ciencia y Empresa de la Junta de Andalucía a través de su convocatoria de Proyectos de Excelencia (referencia P07-SEJ-02574). Los autores desean expresar su agradecimiento al profesorado perteneciente a los centros educativos participantes en el estudio por su inestimable colaboración, así como al alumnado que ha participado en el estudio. 